\title{
Ultra-accuracy parallel electronic datum optical metrology system of systems (Notice of Removal)
}

Xiang-Wen Xiong, Wynn Bear

Xiang-Wen Xiong, Wynn L. Bear, "Ultra-accuracy parallel electronic datum optical metrology system of systems (Notice of Removal)," Proc. SPIE 6829, Advanced Materials and Devices for Sensing and Imaging III, 682925 (29 January 2008); doi: 10.1117/12.765821

SPIE. Event: Photonics Asia 2007, 2007, Beijing, China 


\title{
Ultra-accuracy parallel electronic datum optical metrology system of systems (Notice of Removal)
}

\author{
Proc. SPIE 6829, 682925 (2007); http://dx.doi.org/10.1117/12.765821 \\ Online Publication Date: 26 November 2007 \\ Retracted from Publication: 20 August 2008 \\ Conference Date: 12 November 2007 \\ Conference Location: Beijing, China \\ Conference Title: Advanced Materials and Devices for Sensing and Imaging III \\ Conference Chairs: Anbo Wang, Yimo Zhang, Yukihiro Ishii
}

Xiang-Wen Xiong and Wynn L. Bear

Wynn Bear International Cutting-Edge High-Tech Institute, Inc. (China)

This paper (SPIE Paper 682925) was removed from the SPIE Digital Library on 19 August 2008 upon learning that two individuals listed as additional co-authors on the manuscript had no prior knowledge of the paper, did not contribute to it, and did not consent to having their names included as coauthors. The names of these two individuals have been or will be deleted from this and all other bibliographic records as far as possible since they have no connection to this paper.

Additionally, the remaining names associated with this publication record, Xiang-Wen Xiong and Wynn L. Bear, are actually the same individual and not two different authors. This is not sanctioned by SPIE.

As stated in the SPIE Guidelines for Professional Conduct and Publishing Ethics, "SPIE considers it the professional responsibility of all authors to ensure that the authorship of submitted papers properly reflects the contributions and consent of all authors."

A serious violation of these guidelines is evident in this case. It is SPIE policy to remove papers from the SPIE Digital Library where serious professional misconduct has occurred and to impose additional sanctions as appropriate. 